\title{
Data dissemination by Uganda Bureau of Statistics
}

\author{
Nyangoma Judith ${ }^{1}$
}

\begin{abstract}
Data plays a big role in educating the population on various issues that contribute to development. One of the major activities conducted after data collection is, dissemination of the data to different stakeholders. Uganda Bureau of Statistics disseminates data to its users through a number of channels. This paper discusses each method in detail and how it's used during this process. The major channel of sharing data with users is through dissemination workshops and the website. Other channels used for dissemination include the library and resource centre, social media and physical delivery to stakeholders in district public libraries. Having the above-mentioned channels of data dissemination in place, has helped UBOS remain the centre of excellence in dissemination of data to users, countrywide and in Africa.
\end{abstract}

\section{Keywords}

Data, dissemination, Uganda Bureau of Statistics, Uganda

\section{Introduction}

Uganda Bureau of Statistics (UBOS) is the principal data collecting, processing, analysing and disseminating agency responsible for coordinating and supervising the National Statistical System. Formerly, UBOS was known as the Statistics Department under Ministry of Finance, Planning and Economic Development. It was later on, transformed into a semi-autonomous body by the Uganda Bureau of Statistics Act No. 12, 1998.

The decision to establish the Bureau arose from the need for an efficient and user-responsive agency that would meet the growing demand for statistics on social, economic and political developments in the country. UBOS is, therefore, coordinating the development and maintenance of a National Statistical System which will ensure collection, analysis and dissemination of integrated, reliable and timely statistical information (UBOS, 2020).

UBOS is mandated to develop and maintain an integrated, coherent and reliable National Statistical System (NSS). The Bureau, therefore, has the dual role of producing and disseminating quality statistical information as well as coordinating, monitoring and supervising the NSS. In totality, the Bureau produces key statistics to support and inform the national and international Results Based Management (RBM) development agenda.

The Bureau under one of its Divisions (Communication and Public Relations), disseminates data after having sensitised the public of its intended surveys, carrying out field interviews and final analysis of data. Lots of leaflets concerning the survey are given away to the public. The media is also involved to ensure the public is aware of what is going on in regards to a specific survey. The end-result is the published reports which are well distributed to the public and and some African countries.

\section{Objectives}

The objectives of the study were to:

i. Find out the type of data disseminated by Uganda Bureau of Statistics.

ii. Find out the channels used in data dissemination.

iii. Find out the challenges faced in data dissemination. 


\section{Type of Data disseminated}

The Uganda Bureau of Statistics disseminates socio and macro-economic statistics. The type of data disseminated by UBOS includes, among others, population and social statistics, households, agriculture, business establishments, macro-economic statistics i.e., GDP, Cross Border Trade, Consumer Price Index, among others.

\section{Methods of Data dissemination}

The methods of data dissemination are dissemination workshops, hand-delivery, social media, library and resource centre, word-by-mouth and online delivery.

\section{Channels UBOS uses to disseminate data}

\section{Word of mouth channel of communication}

Wherever we go by use of taxis, motorcycles or on foot, we as UBOS staff tend to find out if the public has heard about us. At least, they are familiar with the population census and household surveys. They, particularly, participate in responding to the questionnaires. Then, we go ahead to tell them the information that we need to be shared with colleagues or their next clients. The same approach is applied to taxi drivers and passengers. By this channel of dissemination, a wide coverage of cities or districts is done, hence fulfilling our aim of data dissemination.

While talking to someone in a taxi or any other type of vehicle, a message is heard from the horse's mouth (UBOS) and easily trusted and at the same time, clearly understood. That way, this person passes on the same message to another. The challenge with the above channel would be an incentive. Most of these people tend to ask for it. The question, these days is, how are they to benefit from passing on the message on UBOS' behalf? However, it's an effective method to pass on data through all those people who use public means or those who tend to have walks. Along the way, you get to walk besides someone, hence initiating a talk.

We intend to make the word-of-mouth channel of communication become official because of its effectiveness. We ensure to get the mobile numbers of the persons/motorcyclists and passengers that we talk to, in order to acquire feedback from them.

\section{The social media channel}

The social media that is normally used for data dissemination is WhatsApp. We also use the email addresses and hence, collect as many as possible. Majority of people no longer make calls to friends, officemates or relatives but find using the WhatsApp and Twitter social media as the easiest and flexible means of communication. This has also extended to the delivery of data to the users and especially the policy-makers. Many groups for such a purpose are now in place, for example, the 'ubosstaff' which has effectively helps to deliver information to staff, especially on the Covid 19 updates through a newly created newsletter that we circulate to friends and relatives, ministries, departments and agencies, who also circulate the information. There is another group in place, named Baseline Education Survey on which we continuously deliver related data.

Websites and emails do a similar purpose but not as effective as WhatsApp and Twitter, from which there is instant information dissemination and feedback. The Uganda Bureau of Statistics website is https://www.ubos.org. It's a necessity for all institutions to make official, the use of WhatsApp and Twitter as an effective method of information delivery.

\section{Hand-delivery channel}

Hand-delivery of data or information is a good channel especially to the districts in the country, that don't have access to internet. Here, you get the chance to discuss further with the officials and get 
feedback if needed immediately. Brochures and publications by UBOS are delivered to them by the help of vehicles, accompanied by an official letter and officer. It would be a good move if the motorcycles are also involved in the delivery of this data. This channel of hand-delivery has been continuously used world-wide before the internet came on board, and we still use it.

As Uganda Bureau of Statistics, this is handy because we always have different ongoing surveys, almost in the same period due to deadline requirements from government and donors. Hence, fuel and transport are always available for data dissemination, without necessarily using only the dissemination budget.

\section{Brochures and newsletter channel}

Use of brochures and newsletters remains a channel for data dissemination. These provide summarised long-term data. These can as well be scanned and placed on any social media of choice, distributed through word-of-mouth, motorcycles and vehicles.

Generally, a lot of hand-delivery is done for data dissemination because of its being handy. The brochures and newsletters normally have between one and six pages. After reading information therein, an individual is free to pass it on to another person or the family for awareness as well as information sharing with neighbours.

\section{The library and resource centre}

The UBOS Library is open to both the public and staff from Monday to Friday, 8:00am-5:00pm. That means, it's able to entertain library users from within and outside. All UBOS publications including those current and past, are found in our library. We ensure all the several displays that we have in the library can have our different products and also have some for take-away. We normally host between 200 and 300 guests per month.

In the library, there is always someone to respond to questions and in event that the request is complicated, we have statisticians and directors from different directorates to give a hand. So, the library users go away with instant feedback from our staff.

The library is privileged to host students, researchers and policy-makers like the legislators, ministers, executive directors, heads of ministries, departments and agencies. They are always excited to receive our data.

All libraries with displays for their products, would be doing their organizations/institutions a great favour since the users of this information take it away for further reading and give-away.

\section{Challenges UBOS faces in disseminating data}

The challenge faced by UBOS is delayed finalisation of the statistical products, i.e., reports, due to delayed receipt of funds from donors and government. Failure to print them in time denies current data to the public.

Timely delivery of products is affected by delay in processing funds to disseminate the information. Fuel for vehicles, allowances for officers to disseminate information in the districts and internet bundles are all affected by the delayed funds.

The challenges to data dissemination include but not limited to: limited funding hence limited surveys conducted, people don't value statistics when they start relating it to politics, motorcyclists request for a bribe in order to deliver or pass on information, lack of internet all over the country hence some intended persons are left out, if it is the only option to be used. 


\section{Recommendation to improve data dissemination}

There is need to have the WhatsApp and Twitter social media officially recognized in delivering and disseminating information to the targeted people or audience. The channels of word of mouth and motorcyclist sharing of information needs to be officially recognized because of their wide dissemination.

\section{Strategies to improve data dissemination at UBOS}

The strategic plan is to use data to make better and faster decisions to as many organisations and individuals, as much as possible. This calls for continued collection of online addresses so that it is posted accordingly.

Presenting our findings in a simple terms so that even the common person can apprehend it, is paramount for the benefit of all intended persons, ministries, departments and agencies.

The continued use of various channels of communication would allow wider information dissemination, countrywide and to Africa.

There is need to widely disseminate the dissemination policy to stakeholders who are involved in data production so that they know what to expect or be done.

Let us make official the use of social media and public means as channels of data delivery because they are fast.

Finally, targeting the right people to whom information can be disseminated is important. For example, reports should be sent to institutions other than individuals after dissemination workshops. That way, the institutions would disseminate it as required.

\section{Conclusion}

Data dissemination is a worthwhile exercise when the beneficiaries utilise the data provided, and later on, continue to share it.

\section{References}

1. The Uganda Bureau of Statistics Library and Resource Centre

2. The Uganda Bureau of Statistics Act No.12 of 1998

3. The Uganda Bureau of Statistics' Communication and Public Relations Manual 2018

\section{Endnotes}

${ }^{1}$ Judith Nyangoma is an Information Assistant at Uganda Bureau of Statistics (UBOS) and can be reached by email: joykuse@gmail.com 